\title{
Consensus rationales in negotiating historical responsibility for climate change
}

\author{
Mathias Friman
}

\section{Linköping University Post Print}

\section{Tweet}

N.B.: When citing this work, cite the original article.

The original publication is available at www.springerlink.com:

Mathias Friman , Consensus rationales in negotiating historical responsibility for climate change, 2014, International Environmental Agreements: Politics, Law and Economics, (), , -24. http://dx.doi.org/10.1007/s10784-014-9258-1

Copyright: Springer Verlag (Germany)

http://www.springerlink.com/?MUD=MP

Postprint available at: Linköping University Electronic Press

http://urn.kb.se/resolve?urn=urn:nbn:se:liu:diva-107221 


\title{
Consensus Rationales in Negotiating Historical Responsibility for Climate Change
}

\author{
Mathias Friman \\ Centre for Climate Science and Policy Research (CSPR), Linköping University and the Swedish \\ Meteorological and Hydrological Institute (SMHI)
}

Water and Environmental Studies, Department of Thematic Studies, Linköping University.

mathias.friman@liu.se

\begin{abstract}
This article explores strategies in consensus-making processes in international climate diplomacy. Specifically it examines the consensus-making politics, in the case of negotiating historical responsibility within the UN Framework Convention on Climate Change (UNFCCC). In doing so, analytical concepts from the discourse theory of Laclau and Mouffe are utilized to look for rationales that underpin discursive structures as well as agreement. To conclude, three rationales have dealt with conflicts over historical responsibility. While the first rationale hid conflict behind interpretative flexibility, the second reverted to "reasoned consensus," excluding perspectives commonly understood as political rather than scientific. The third rationale has enabled equivocal use of the concept of historical responsibility in several parallel discourses, yet negotiators still stumble on how to synthesize these with a potential to foster future, more policy-detailed, consensuses with higher legitimacy. Understanding the history and current situation of negotiations on historical responsibility from this perspective can help guide policy makers towards decisions that avoid old pitfalls and construct new rationales that generate a higher sense of legitimacy.
\end{abstract}

Keywords: climate negotiations; consensus; legitimacy; historical responsibility 


\section{Introduction}

It is common practice in multilateral environmental negotiations to strive for consensus on all matters of substance. Because of the transboundary nature of global environmental problems, as noted by Depledge (2005), "committed participation of all states is viewed as critical" (p. 92). Hence, diplomats involved in these processes avoid voting since it impacts legitimacy among overruled Parties, restraining ratification and implementation. Due to the inability of Parties to the United Nations Framework Convention on Climate Change (UNFCCC) to adopt rules of procedures, caused by disagreement over paragraphs regulating voting, the consensus orientation in UN-led climate cooperation is particularly strong.

It has become widely accepted in international environmental law to differentiate states' responsibilities based on contributions to environmental problems (Ringius, Torvanger, \& Underdal, 2002). In the case of climate change, however, contributions to the problem have an unusually long temporal dimension. Emissions of greenhouse gases accumulate and persist in the atmosphere, or the memory of their effects are stored in other parts of the climate system, connecting past emissions with present and future climate change in a very direct manner (Höhne $\&$ Blok, 2005). Consensus on how past contributions to present and future climate change should be assessed as to underpin differentiation of responsibilities has proved particularly hard to reach in the UNFCCC. While responsibility distribution is the core task for the UNFCCC that motivates its existence as a forum for interstate negotiations, the moral significance of historical contributions to climate change for responsibility negotiations has been highly debated. Ever since negotiations for the UNFCCC commenced in 1991, differentiation of responsibilities based on past emissions has been a heated topic where consensus has been hard to forge. The concept of historical responsibility eventually crystalized from these early negotiations, and slowly gained recognition during the late 1990 s as an important node for negotiating differentiation.

UNFCCC. In the context of unsettled voting regulations, practically granting veto rights to every Party (Depledge, 2005; UNFCCC, 1996), historical responsibility is an interesting case for understanding how consensus is built on the highly conflictive issue of responsibility distribution. Arguably, consensus should foster a high sense of legitimacy, however the case of historical responsibility shows that agreements have been struck by avoiding rather than confronting core conflict. By elaborating and applying an analytical framework from discourse theory, this article aims to understand efforts to build consensus in over 20 years of negotiating historical responsibility. Specifically, it poses three questions:

- How has discourse on historical responsibility been structured in UNFCCC politics?

- What rationales have underpinned consensus on historical responsibility?

- What can be learnt from how historical responsibility has been negotiated for the future of the UNFCCC process?

After having briefly introduced the history of UNFCCC negotiations and its rules of procedure to substantiate the understanding of consensus, the article then turns to methods for gathering and analyzing the empirical material. This section discusses (1) an analytical framework for understanding different interpretations of historical responsibility, (2) discourse theory to elaborate an analytical framework for understudying structure and rationales, and (3) the method for data collection. In a next step, the analytical frameworks are applied in analysis of the structure of discourse on historical responsibility throughout the years 1990-2010 resulting in the identification of three rationales that have been used to underpin consensus. In the following discussion, the article explores reasons why these rationales were successful in forging consensus while obscuring conflict. The rationales have had different political effects - not least on the perceived legitimacy of the outcomes-yet the current rationale could potentially increase legitimacy of future outcomes on historical responsibility by more fully illuminating conflict on the road to and in consensuses. The article concludes in pinpointing what could be learnt from the case of historical responsibility negotiations for the future UNFCCC process. 


\section{Background: UNFCCC negotiations and consensus making}

The almost universally accepted UNFCCC provides a framework for international responses to climate change. Its supreme body, the Conference of the Parties (COP), has negotiated since 1995. Most developed countries, specified in Annex 1 (A1), have accepted strengthened commitments under the Convention's only protocol, the Kyoto Protocol (KP). Its first commitment period run from 2008 to 2012. In 2005, the first COP serving as the Meeting of Parties to the KP (CMP) commenced negotiations for a second commitment period. In parallel, COP11 launched informal talks on long-term cooperation under the Convention, formalized by COP13 in 2007. Since then, the regime has had two Ad hoc Working Groups, one negotiating Further Commitments for Annex I Parties under the Kyoto Protocol (AWG-KP) and one negotiating Long-term Cooperative Action under the Convention (AWG-LCA). However, at COP17 in Durban 2011, it was agreed that the AWG-LCA should finalize its work during 2012. A new ad hoc group, on the so-called Durban Platform (ADP), should continue the work towards an agreed outcome with legal force beyond 2020. In negotiations for a future climate agreement under ADP, historical responsibility is very likely an issue that will continue to engage negotiators, which makes understandings of its negotiating history important to be able to avoid old pitfalls.

Besides the COP/CMP and subsidiary ad hoc groups, the regime includes two permanent Subsidiary Bodies: for Implementation (SBI) and for Scientific and Technological Advice (SBSTA), advising COP/CMP within their mandates. Negotiations in the Intergovernmental Negotiating Committee (INC) drafting the UNFCCC, as well as those of both COP and CMP, for this issue organized mostly under SBSTA and a number of ad hoc subsidiary bodies, provide the frames of the focus in this article.

Each Conference to a MEA in the UN family, independent as they are, is required to adopt its own rules of procedure (Sabel, 2006). After adopting the UNFCCC in 1992, and before its entry into force in 1994, the intergovernmental negotiating committee continued preparatory negotiations for COP1 to "jump start" its work. This process also included preparing draft procedural rules. The rules were modeled on standard UN negotiating procedures, corresponding generally to those applied in the UNGA (Yamin \& Depledge, 2004) and specifically to the procedural rules of the Basel Convention on the Control of Transboundary Movements of Hazardous Wastes and their Disposal (UNFCCC, 1996).

Rules of procedure of international organizations are normally adopted by majority vote (Seyersted, 2008). The UNFCCC, however, stipulates that the procedural rules of its COP must be adopted by consensus (UN, 1992a: Article 7.2(k)). COP1 in 1995 failed to adopt the draft rules, primarily because of disagreement over rule 42 on voting. Although the disagreements on voting extend beyond a single locus, one crux is that the UNFCCC does not specify a majority requirement for adopting protocols (cf. Article 17). Without voting procedures, one Party could therefore potentially block a protocol acceptable to the remaining 193 Parties. Two options were proposed for how to settle matters of substance through Rule 42, i.e. a) adoption by two-thirds majority and b) adoption by consensus (UNFCCC, 1996), but agreement could not be reached.

Since COP1, continuous informal consultations have been held attempting to find common ground between the two options; for example, middle-ground proposals suggest using either a threequarters or seven-eighths majority as a last resort to settle disagreement (UNFCCC, 1997c). So far, however, adoption has been impossible and all COPs have applied the draft rules of procedure with the exception of rule 42 (cf. UNFCCC, 2013: §4-6; Yamin \& Depledge, 2004).

In lack of agreed rules of procedure in the UNFCCC, the negotiations have applied draft rules with the exception of rule 42 on voting (see UNFCCC, 1996). While voting on matters of substanceas opposed to procedural matters - has so far not been an option when draft rules have been applied, the UNFCCC and the KP allows for the adoption of amendments and annexes by a 3/4 majority (UN, 1969: Article 16 and 17; UNFCCC, 1998a: 20 and 21). Yet it should only be reverted to as a last option, when all efforts to reach consensus have been exhausted, and it is 
coupled with the possibility of individual Parties' non-acceptance of the decision. In practice, voting has been avoided under both the UNFCCC and the KP, not least since it may result in Parties being bound by different versions of the Convention or the Protocol.

In the absence of voting procedures, decisions have required consensus, in the sense that there is an absence of formal objection (Depledge (2005). Consequently, consensus making processes have become central to UNFCCC negotiations. Voting on matters of substance is almost never prompted as an option and has never been practiced. All views of all UNFCCC Parties are therefore validated by the fact that Parties can exercise close to veto rights. On the other hand, the presiding President of the COPs is - in the absence of clarity on rules - granted some leeway in interpreting the concept of consensus. At some instances, this flexibility has been used to gavel decisions despite formal objections in plenary sessions (e.g. in Kyoto 1997, Cancún 2010, and Doha 2012), acts that overruled common practice based on interpretation that consensus does not equal unanimity.

The ambiguity granted to the draft rules of procedure makes consensus building an interesting object of study. The strong consensus orientation in the process specifically underscores the need to understand consensus-making processes to also understand the broader question of what outcomes that could viably be expected from an organization like UNFCCC.

\section{Theory and method}

\section{Analytical framework for categorizing different versions of historical responsibility}

Analytically speaking, two opposing understandings of historical responsibility have emerged in both science and politics: a conceptual and a proportional perspective (Friman \& Strandberg, 2014). The conceptual view structures historical responsibility as an abstract notion for concrete action. The moral significance of history depends on whether the current state-of-the-art in international relations has come about in a fair manner. If, for instance, historical accumulation of wealth to certain areas has been unjust, capacity given by this wealth renders a historical responsibility to act (cf. Caney, 2006; Cordonier Segger, Kahlfan, Gehring, \& Toering, 2003: 5051). In UNFCCC, this often translates into claiming that A1 Parties, which have the greatest capacity to act, should act concretely before demanding the same by non-Annex 1 countries (NA1) (cf. Rajamani, 2000; Ringius et al., 2002; Stone, 2004, 292-293). In contrast, the proportional view assigns responsibility of states or regions relative to their contribution to climate change. It attributes change-for example, as indicated by mean surface temperature-to historical emissions and translates this into relative responsibilities (cf. Müller, Höhne, \& Ellermann, 2007; Neumayer, 2000; Ringius et al., 2002; UNFCCC, 1997a).

Along with the views held by proponents of no historical responsibility, these perspectives can be used to capture the span of conflict that has been visible among Parties throughout the last 20 years of international negotiations on climate change.

\section{Utilizing discourse theory to account for structure and rationales in negotiations on historical responsibility}

Consensus making arguably takes place through communication, which have been studied from several perspectives. Researchers schooled in international law, for example, are particularly well appointed to understand the legal structure in which negotiations occur, as well as discussing legal interpretations and implications of outcomes. Political scientists have been particularly good at understanding motives for certain positions as well as power recourses used in politics. Such approaches many times view international negotiations as an arena where government representatives meet to maximize the alignment of outcomes with the instructions that incarnate governments' self-interests. Such and other frameworks for understanding what takes place in and through the communication between diplomats are vital. However, the need for consensus making to successfully generate a sense of legitimacy in collective outcomes also point toward the importance of understanding UNFCCC as a forum for deliberation seeking mutual understandings on a problem of common concern in parallel to viewing it as a stage for coercion through power 
politics (Hurd, 1999, 2011). Discourse theory delivers a strain of thought that provides tools for conducting analysis with such a departure point, a tool that will be utilized and explored further in this article.

Most contemporary discourse theory sees the world as socially constructed through language (Alvesson, 2003; Bergström \& Boréus, 2005). This means that knowledge of the world is created through social interaction and that this knowledge is specific to the historical situation.

Accordingly, language does not reflect objective reality; instead, it is impossible to escape the fact that our knowledge of reality is constructed through the use of language (Butler, Laclau, \& Žižek, 2000; Hajer, 1995; Laclau \& Mouffe, 2001).

Fariclough (2003) divides discourse theory into two camps, one inspired by linguistics and the other drawing on the work of Foucault. The first is more suitable for detailed content or narrative analysis of text and tends to avoid the "social theoretical issues," whereas the second focuses on how discourse engages, for example, in "the socially 'constructive' effects of discourse" (Fairclough, 2003: 3)). The second is also suitable for investigating the evolution of discourse over longer periods and across a larger empirical material.

To answer questions on structure and rationales in negotiations on historical responsibility, this article employs discourse theory of Laclau and Mouffe. Their theory departs from an understanding of reality as constituted through discourse (Laclau \& Mouffe, 2001). As such, it differs from discourse theory that, for example, views certain deliberated ways of arriving at consensus as a means to eliminate rather than veil power (Gottardis, 2007). The starting point that closure, although much needed, also inevitably excludes alternatives makes the theory of Laclau and Mouffe particularly rewarding for analyzing a trait in negotiations on historical responsibility: despite longstanding efforts to build consensus, core conflict on this issue continues to occupy the agendas (Friman \& Linnér, 2008; Friman \& Strandberg, 2014). Discourse theory that focus on arriving at deliberated consensus, as a rational process that eliminates disagreement and the use of power is ill equipped to explain this trait in negotiations on historical responsibility. For international politics involving decentralized legal systems - such as the UNFCCC, which lacks a strong autonomous dispute settlement system - investigating the opportunities and limitations of discourse in the UNFCCC is important, as it contributes to a justificatory discourse for assessing states' degree of compliance with international law (Johnstone, 2011).

Discourse, according to Laclau and Mouffe, attempts "to dominate the field of discursivity, to arrest the flow of difference, to construct a center" (Laclau \& Mouffe, 2001: 112). To construct centers, relationships between signifiers are structured through articulation that specifies and modifies their meaning (Laclau \& Mouffe, 2001: 105). For instance, discursively, the signifier "historical" can come to mean anything. It is not naturally tied to a specific phenomenon that it can represent in a direct and uncomplicated manner. In practice, however, existing discourse on for example "historical responsibility" typically connects "historical" to a structure that carries a distinctly different meaning than if structured slightly differently as for example "historical times."

When articulating discourses, some signifiers — nodal points—get privileged status. "Historical responsibility," proves a certain centrality in signifying, say, "past emissions" or "contribution to temperature increase." Without structuring these in relation to the connecting node made up by "historical responsibility", their ambivalence would increase. Conversely, connecting the less central signifiers to nodal points is what makes up the centrality and signification of nodes.

Thus, discourse structure signifiers in certain patterns that are possible to map. However, the concept of rationales is more subtle. One way to operationalize it is to refine the notion of privileged signifiers to understand the diverse mechanisms by which closure is achieved around specific structures. 


\section{Analytical framework to understand rationales: Filled, emptied and floating signifiers}

Laclau and Mouffe understand discourse as spanning from close to no structure to total structure. The above-mentioned field of discursivity is the place of sheer difference. At the opposite end of the scale - i.e. total structure - all signifiers are completely locked in relation to each other. Such a condition would represent a rigid system of pure repetition with little space for restructuring signifiers to create new or competing meaning; it would represent an ultimate hegemony erasing all other discourses, and thus erasing discursive struggles.

Complete autonomy and complete hegemony of discourse therefore represents the same phenomenon: the impossibility of negotiations. In complete flux, the autonomy of every statement would produce mere noise. In a completely structured totality, the resulting totalitarian system would produce repetition of what is already agreed. Empirically, this never occurs. Discourse is always situated between complete discursivity and hegemony. This is also what creates room for communication and antagonism, and what paves the way for democratic politics and the need for negotiations of conflicts (Laclau, 2000a: 305).

The archetypical endpoints provide an analytical scale along which enables distinguishing different rationales to achieve discursive closure around central signifiers. To enable speaking of the construction of hegemony, as opposed to discourse, Laclau differentiates between central signifiers in general (nodal points) and so-called empty signifiers (Laclau, 1996: 36; 2000b: 66). Drawing on Jørgensen and Phillips (2002), emptiness signals arbitrariness of a nodal point rather than a more autonomous signifier that occurs as central in several parallel discourses (Laclau, 1996: 36). The first represent discourse whose structure is underpinned by rationales that create autonomy by distinguishing and excluding clear alternatives, i.e. that are closer to discursivity than hegemony. The other represents the opposite: discourse structured around rationales that internalizes and submerge difference.

However, to signal the contamination by particularity in empty signifiers, complete emptiness is here distinguished from emptied signifiers. The concept of an emptied signifier is intended as a reminder that a particular discourse has taken on the character of a naturalized totality, favoring repetition over re-definition.

A filled signifier, on the other hand, signals that a particular discourse has come to represent a distinct notion of a concept, with little arbitrariness, that is effectively guarded. Unlike with emptied signifiers, the corresponding signified can appear with several autonomous significations while communication between discourses is poor or lacking.

Finally, the scale between the archetypical endpoints of complete particularism as well as totalitarianism is here, in Figure 1, depicted as circular in that the endpoints meet in restricting democratic politics through limiting antagonism by making negotiations impossible. Across from this point lies antagonism, that is, open struggles between discourses over structuring central signifiers in one rather than other ways. A privileged signifier in such a situation is distinguished as floating. The floating signifier can be used in many different discourses that openly compete for the right to gain the privileged interpretation of a concept. 
Fig. 1 Analytical framework

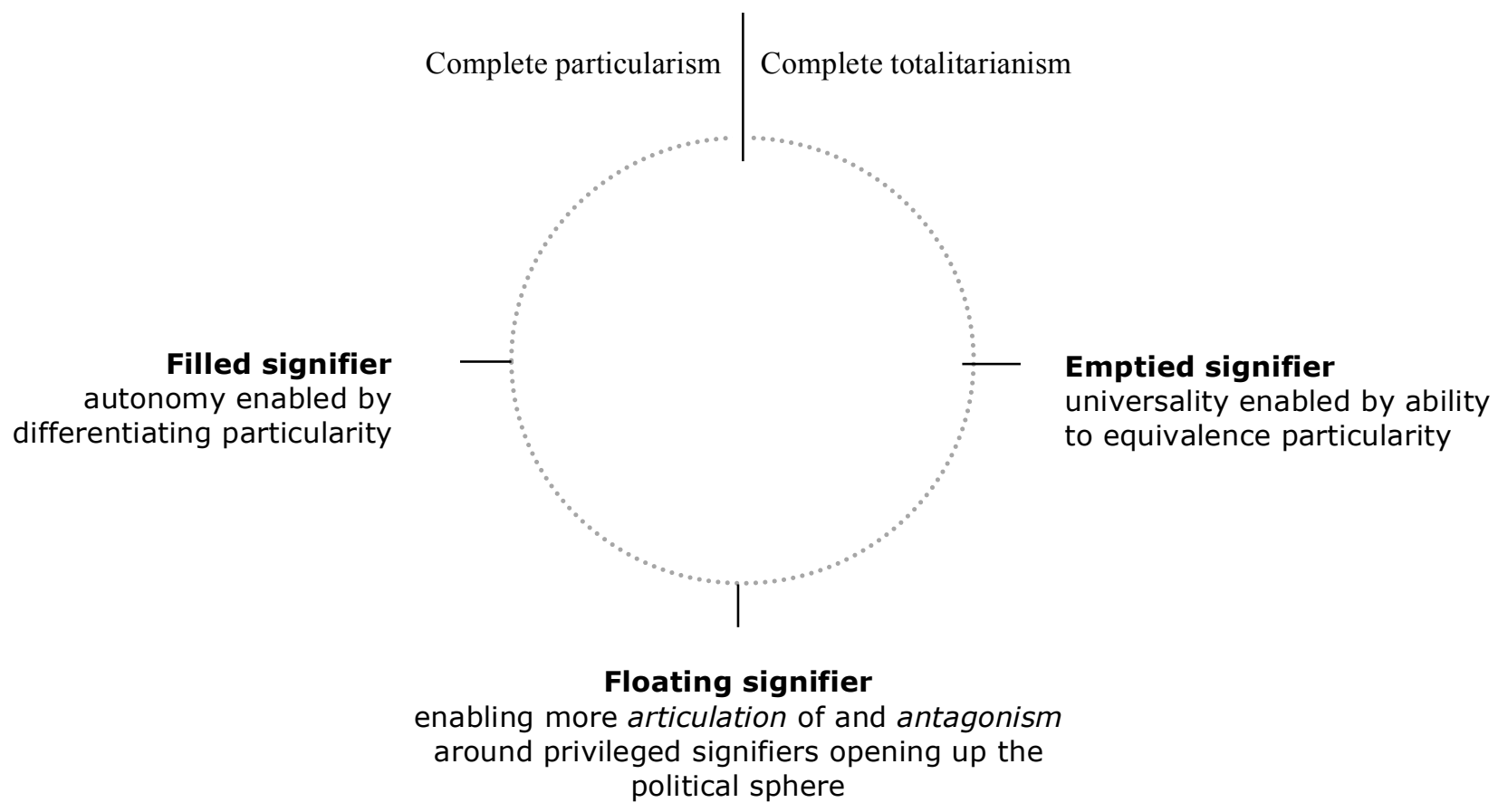

This analytical framework, here elaborated based on the discourse theory of Laclau and Mouffe, enables to account for different rationales that underpinned discourse in general, and consensus in specific, through treating conflict through different mechanisms that result in exclusion of alternatives characterized through: 1) closing structure based on filling; 2) emptying; or 3) by allowing central signifiers to float in various discourses.

\section{Method}

The following material has been used: negotiation documents (1990-2010) retrieved in sessions and from the UNFCCC website (www.unfccc.int); reporting services (Earth Negotiations Bulletin); observations of webcasts (1997-) and 13 negotiating rounds (2007-2013); and six in-depth, semi-structured interviews with key actors (conducted in 2008-2009).

Initially, keywords with relevance to historical responsibility were singled out through qualitative reading of official documents. Iteratively new text and keywords were added through computeraided searches, resulting in the following keywords:

- $\quad$ historic/-al responsibility/-ies, emissions, and contribution

- carbon/climate/natural/ecological debt

- cumulative/accumulated/past emission/-s

- $\quad$ polluter pay/-s principle (PPP)

- "Brazilian proposal" and "proposal by Brazil"

These searches helped construct the contours of a "raw" discourse of how, when and in what forum historical responsibility has been articulated. However, when Parties' proposals are transformed to compilations, and further to Chairs' texts to facilitate negotiations and official negotiating texts, much of what was proposed and negotiated yet not agreed fall outside the scope of these documents. The reporting service, observations and interviews therefore have served the purpose of capturing articulations that have not sedimented into these consolidated texts. Once the 
raw discourse took shape, more targeted observations and interviews have been used to supplement the core material A similar screening was made for "differentiated responsibility," which served to situate historical responsibility in a wider responsibility discourse.

Identifying centers has been based on the degree to which articulations return to such signifiers, both between Parties and across time. The emerging maps of discourse are a result of a qualitative coding exercise that determines the centrality of some signifiers to construct meaning of other signifiers. It should not be red as an exercise of quantification through content analysis. To exemplify why the qualitative reading is preferred over the quantitative for mapping of discourse in this type of analysis, some signifiers can indeed be referred to several times, although making little sense without connecting to a central element which may only be mentioned once but which provides the core framework for an intervention.

\section{Structure and rationale of discourse on Historical Responsibility in UNFCCC politics}

To speak of the structure of discourse, the continuously evolving discourse is divided into five temporal periods. These periods mark important shifts in the discourse on historical responsibility. Each will therefore be discussed separately, and then contrasted with the others. Three discursive rationales have actively structured historical responsibility discourse during these periods. In summary, the first rationale hid conflict behind interpretative flexibility (emptied the concept), the second reverted to reasoned consensus excluding standpoints that are commonly understood as political rather than scientific (filled the concept). The third rationale has enabled equivocal use of the concept in several parallel discourses (made it floating), yet negotiators still stumble on how to treat them in consensus outcomes.

Four figures (2-5) illustrate this temporal evolution of discourse on historical responsibility, each comprising schematic images of relations between important signifiers in discourse. Solid lines symbolize established UN General Assembly (UNGA) or treaty text (UNFCCC and its KP); dotted lines signal text that is not yet legally binding - i.e. ratified in national parliaments or equivalent - but central in the policy process through being politically guiding (including $\mathrm{COP} / \mathrm{CMP}$ decisions and conclusions by subsidiary bodies); large circles highlight more privileged signifiers; and small circles connote important yet less privileged signifiers primarily structured under more central signifier(s). Since the principle of Common but Differentiated Responsibilities (CBDR) was soon established as a central policy driver for responsibility discourse in general (Stone, 2004), the figures reflect this principle by indicating signifiers that are primarily concerned with differentiation in grey and universalization in white.

Fig. 2 Early pre-Rio negotiations (1990-1991)

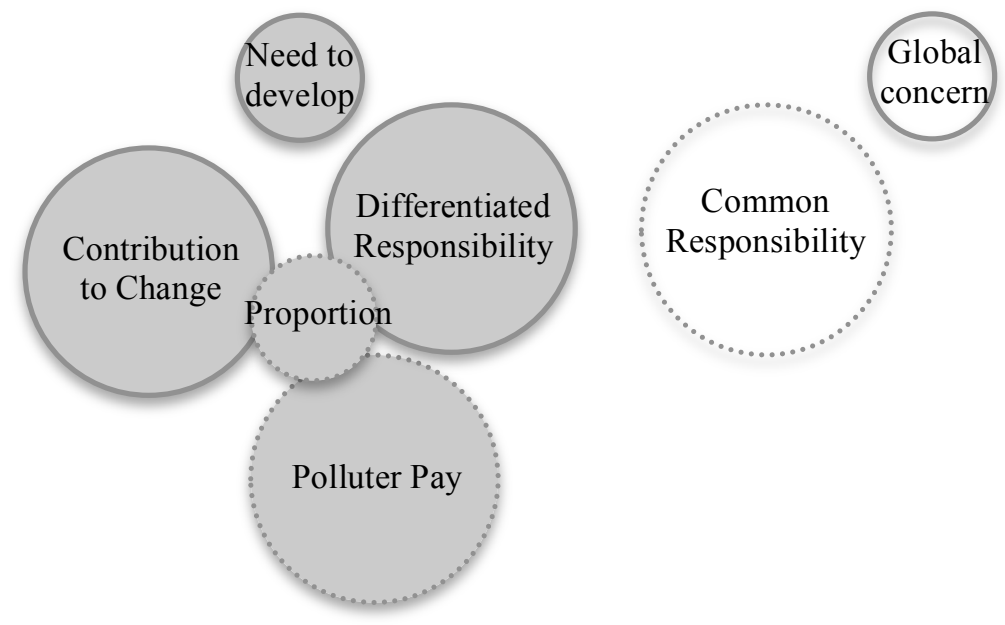


Fig. 3 The Convention

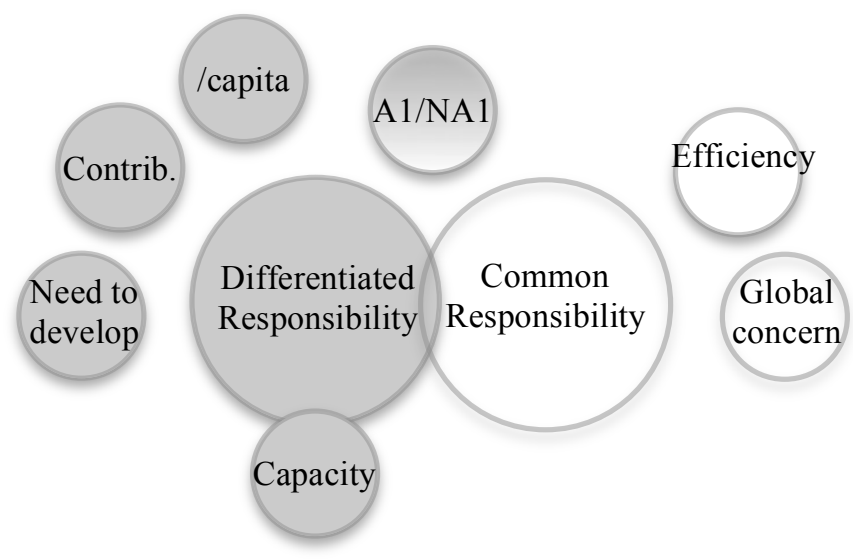

Fig. 4 Pre-Kyoto negotiations and SBSTA (1997-2008)

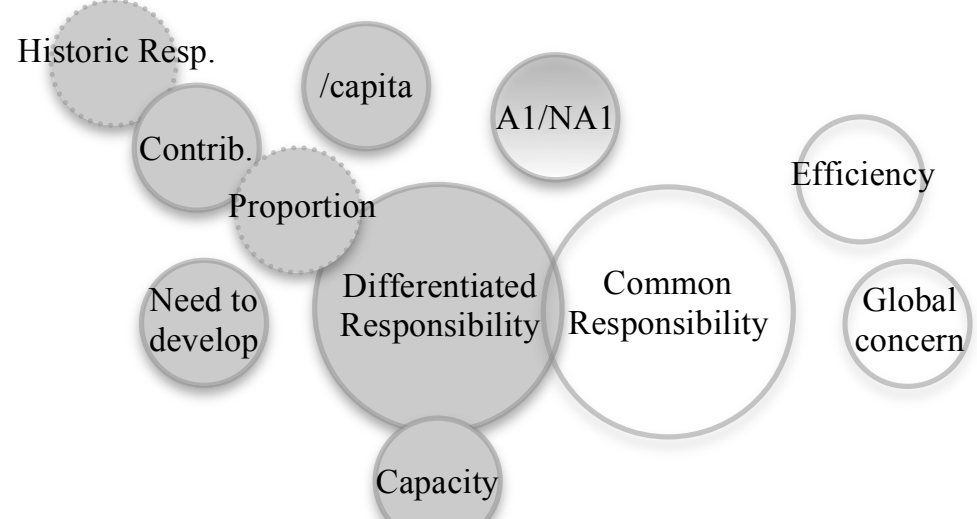




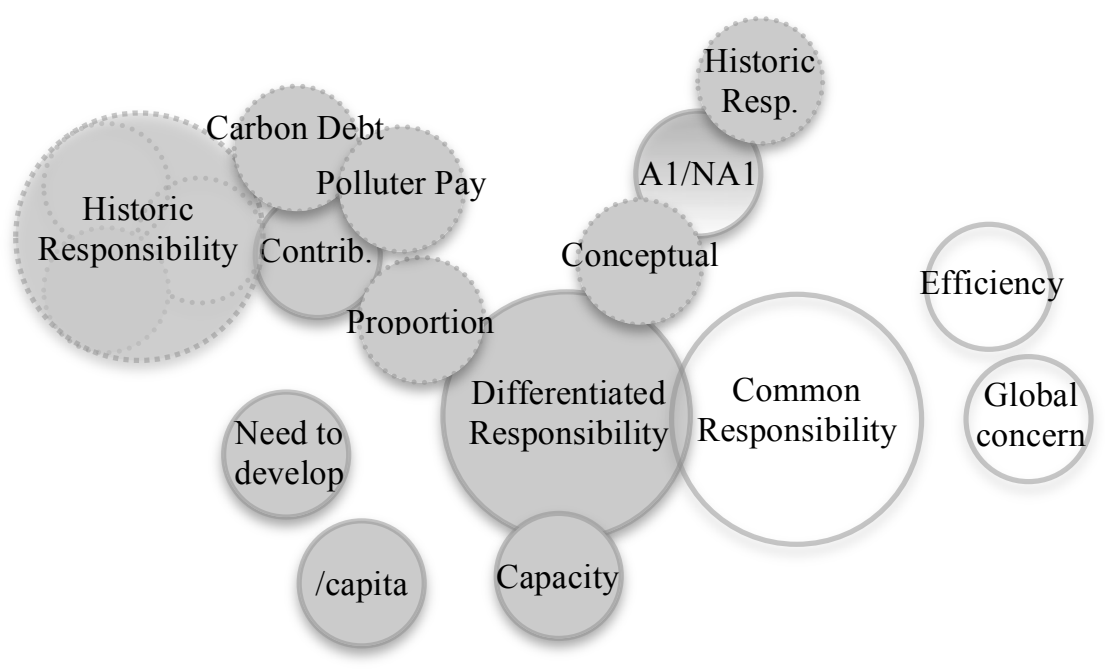

\section{1993: emerging discourse on historical responsibility}

In late 1990, UNGA mandated an Intergovernmental Negotiating Committee (INC) to draft the UNFCCC with a deadline set to coincide with the Earth Summit in Rio, 1992. The UNGA mandate, by reference to resolution $44 / 228$, introduced that responsibility to act must be in relation to the damage caused (UN, 1990: 2). Early INC negotiations refined this writing by visibly signaling proportionality between past emissions and responsibilities (see e.g. UN, 1991a: pp. 13; 1991b: 2, 4, 6 and 13-16; 1991d: 18; 1992b: 27; 1992c: 28). For instance, Vanuatu proposed "governing principles" stating that the PPP, "the principle that those responsible for causing damage to the environment bear the responsibility for rectifying that damage," should be a foundation on which to construct the UNFCCC. The proposal continues, actions "should be based on equity, in accordance with the proportionate contribution to the problem" (UN, 1991b: 16 (governing principle c. and e.)). Articulating PPP in connection to historical contribution began to construct proportionality between contribution and responsibility, at INC3 vaguely structured as responsibility to pay or to rectify damage due to accumulated emissions (UN, 1991b: 4). This constituted the embryo of discourse explicitly referring to historical responsibility.

UNGA also set down climate as an issue of "global concern," urging Parties to call for common responsibilities. Even though this was less clearly articulated in connection to differentiated responsibility at this point of time, it was importantly used to counterweight the significance of differentiation.

Figure 2 provides a visual aggregation of the emerging structure of discourse between and underscores that responsibility to act respective liability to pay was explicitly articulated by structuring it in relation to proportionality. The arguments for historical responsibility (to pay or act) became a function of historical contribution. The argument for common responsibility was still articulated separately from the debate on differentiation and historical responsibility yet it soon merged with differentiated responsibility to form one attractive, yet as will be discussed, problematic policy guiding principle, i.e. CBDR.

Already in INC2 submissions, an emerging principle of CBDR was proposed in direct connection to historical contribution (see e.g. UN, 1991b: 13; UN, 1991c). This was further pursued, as expressed, for example, during INC4 in several options to a proposed responsibility principle. For example: "in accordance with common but differentiated responsibilities [...] taking fully into account that the largest part of emissions of greenhouse gases have been originating from developed countries" (UN, 1992b: 27). 
The continued emphasis on linking historical contribution and responsibility resulted in a proposed Article 2.3 (contribution and CBDR) and 2.8 (contribution and rectification) (UN, 1992c). Importantly, however, the proposals were no longer articulated as necessarily establishing proportionality between contribution and responsibility. During INC5(II), in drafting the final outcome, the connection of contribution to compensation was also dropped. Further, contribution was moved from closely relating to CBDR to a preambular statement that "the largest share of historical and current global emissions of greenhouse gases has originated in developed countries" (UN, 1969: Preamble). Differentiation was also, explicitly, anchored in capabilities, and indirectly in per capita emissions and the need for development (particularly in NA1).

Figure 3 summarizes the privileged signifiers in discourse on (historical) responsibility as structured in the final version of the Convention. The importance of historical contribution became open to both a conceptual and proportionality interpretation by disconnecting it from explicitly asking for a differentiation in proportion to contribution. However, many Parties still viewed them as straightforwardly linked (Müller 2002). CBDR (including historical responsibilities) was seen as principally operationalized by dividing Parties into A1/NA1, blocks of countries with different tasks, although sharing a common objective. Diverse understandings of the principle for distributing clear reduction or finance commitments would prove to be a highly contentious matter. The radical shift in the early compared to the late INC discourse on historical responsibility was found elsewhere: to avoid structuring historical contribution in connection to PPP (compensation/rectification) and/or proportionality.

\section{The rationale of emptying historical responsibility}

During the late pre-Rio negotiations, CBDR took on the character of being emptied. Equivalence between different ways of articulating historical responsibility was made possible by merging articulations on common and on differentiated responsibilities to CBDR-with all its potential internal tension-constructed as constitutively different from either strictly common or strictly differentiated responsibility. Contribution was separated from, yet affiliated to, this new notion of CBDR.

In the UNFCCC strive for consensus and to build legitimacy, conflictive perspectives cannot simply be ignored; every sovereign state has the right to voice its stakes as one among peers. In the case of conflict between proponents for no, as well as proportional or conceptual understandings of, historical responsibility, emptying the central signifier "responsibility" enabled consensus. This did not necessarily solve conflict, but since conflict was pushed into the realm of interpretative flexibility, every Party could agree to their own interpretation as incarnated in the emptied signifier. The late shift away from connecting contribution to PPP, in favor of the connection to CBDR, was indeed a radical shift in the early discourse: it structured historical responsibility as potentially a conceptual instead of a clear proportionality principle. The Convention in fact never explicitly refers to a "historical responsibility." Instead it was only implicitly agreed by understanding contribution as linked to differentiated responsibility. This further emptied the signifier and enabled even more interpretative flexibility. Historical responsibility discourse emerged, yet did not produce explicit treaty text, while conflictive perspectives became hidden behind a rationale to empty historical responsibility of content.

\section{1997: Reopening the political sphere}

From the opening for signature of the UNFCCC in 1992 until its entry into force in 1994, equivocal significations of historical responsibility remained hidden behind the emptied CBDR. Yet in late post-Rio negotiations (during INC10-11), the historical responsibility discourse would become affected by struggles over the preferential right to interpret CBDR. New and distinct articulations on CBDR emerged, signaling its ability to equivalence several divergent positions in Rio. While, concurrently, the strongest advocates for historical responsibility were developing countries, the inducements to reopen the debate on responsibility came from developed countries. 
For instance, Australia proposed a common responsibility among A1 Parties, interpreted as safeguarded by differentiation based on a "broadly equivalent economic costs on a per capita basis" (UN, 1994: 4). Likewise, Russia suggested to base commitments on emissions per capita and land area (UN, 1995: 3), and Switzerland proposed a new Annex, including "rapidly industrializing country Parties" (UN, 1994: 25). Similar articulations challenged the loose structure around CBDR, as mentioned, vaguely understood as implemented by dividing the common objective of world states into differentiated responsibilities for A1/NA1. In the process leading towards the KP, Norway and Japan announced that commitments among A1 Parties were to be differentiated based on energy efficiency within countries (ENB, 1995). Previously, many Parties agreed that differentiation based on historical contribution could represent A1 Parties taking a collective historical responsibility, although the issue of whether it was to be understood as proportional or conceptual had not been settled. What Norway and other countries did was open the door for further differentiation between Parties. If historical responsibility would remain or gain importance as the principle for differentiation in connection to CBDR, it would have to be positioned in this struggle (Interview, 2008b, 2008c). Since this door had been reopened, historical responsibility could again be articulated as relevant not only to the collectives A1/NA1 but also to differentiate within these categories.

The Brazilian government acted on this possibility and drafted a proposal that returned the focus of responsibility negotiations toward proportionality:

The principle of the common but differentiated responsibilities between Annex I and non-Annex I Parties arises from the acknowledgment by the Convention that the largest share of historical and current global emissions of greenhouse gas has originated in the developed countries. [...] It is possible to assign relative responsibilities to the ensemble of Annex I countries and non-Annex I countries according to their respective contributions to climate change, as measured by the induced change in climate. (UNFCCC, 1997a: 5).

Brazil proposed assigning equal responsibility for historical contribution globally claiming that all states had a common responsibility. This common responsibility was to be differentiated in proportion to states' historical contribution to average global temperature increase. When introduced, cutbacks proportional to individual countries' past contributions became an officially acknowledged negotiating item. It would come to mark a somewhat new and certainly much more comprehensive and more closely specified articulation of historical responsibility, one that would set the agenda for several years to come.

The reopened political sphere concerned with historical responsibility allowed antagonism between distinct options only for a short time. Soon, a new consensus rationale emerged that excluded core conflict.

\section{2007: Rationale of objectivity (historical responsibility as filled signifier)}

The introduction of the Brazilian proposal began a new phase of negotiations marked by a different consensus rationale profoundly connected to a traditional view of the promises of science. Science, here, strives to deliver facts as support for political decision-making (Bourdieu, 1981; Sarewitz, 2004), which seems to have been accepted as given among Parties. Placing historical responsibility within the confines of fact-producing science, for good or bad, placed limits on what could be deliberated.

No elements of the Brazilian proposal were included in the draft protocol forwarded to COP3 (UNFCCC, 1997b). However, COP3 reacted to an oral report by asking for further consideration by SBSTA (UNFCCC, 1998a: 59; 1998b: 15). SBSTA is designed to be a "link between the scientific, technical and technological assessments and the information provided by competent international bodies, and the policy-oriented needs of the Conference of the Parties" (UNFCCC, 1995: 21). Although SBSTA's Terms of Reference are open to interpretation, SBSTA-in line with the traditional view of science-focuses more on what is perceived as "hard" science. The first instance of clearly articulating discourse on historical responsibility in this traditional scientific 
context, however, was initiated by Brazil during a set of SBSTA-endorsed workshops organized by the Brazilian government (den Elzen et al., 1999; UNFCCC, 1998c, 1998d).

The workshops identified several flaws in the original methodology of the Brazilian proposal. Even though Brazil seemingly never intended the model as anything but an illustrative example, the government tried to correct the flaws (Interview, 2008c; Meira Filho \& Miguez, 2000; Miguez, 1997). Out of this process grew the specific focus that would continue to engage researchers and negotiators for a long time: i.e., a focus on scientific methods to establish a relation between contribution and indicators of climate change. On this followed two expert workshops organized by the UNFCCC Secretariat after which SBSTA referred the issue to the "scientific community" (UNFCCC, 2003) to inform the negotiations. An expert group was formed that soon became known as MATCH (the ad-hoc group on Modeling and Assessment of Contribution to Climate Change) (MATCH, 2003). In several occasions SBSTA took note of MATCH reports (see e.g. UNFCCC, 2004: 20; 2006d: 14-15). When SBSTA finally closed the agenda item, in 2008, noting that the results of the work could be useful for other negotiation settings (UNFCCC, 2008b), historical responsibility was indeed already emerging in other fora, especially on the AWG-KP and -LCA agendas.

Discourse on historical responsibility was then constructed around the argument that science could serve to sort out differences and uncertainties in and among various options for establishing proportional links between contribution and responsibility. Conflict had to play out more implicitly by debate over what climate modeling of contribution to change ought to include. In the name of objectivity, several aspects of historical responsibility previously framed as "moral" or "ethical" became hard to address. Thus underpinning consensus based on a rationale of objectivity closed the discourse to alternative articulations by effectively filling some of its privileged concepts. Brazilian and Chinese Party delegates indicated this by regretting that, although useful, the work had been too constrained and had failed to produce political outcomes (Interview, 2008a, 2008c, 2009).

Even if the proportionality view has produced a number of consensuses at the subsidiary level, so far it has never materialized in the form of legally binding texts or decisions. The structure of discourse on (historical) responsibility, during this time, is summarized in figure 4. It underscores that proposals to differentiate responsibilities was again beginning to be based on proportionality with historical contribution. This had the outspoken intention to operationalize CBDR, and was always structured in relation to this privileged signifier.

How, then, was it possible that NA1 countries focusing on historic responsibilities were willing to accept discussions on historical responsibility under the rationale of objectivity? The consequences of this rationale clearly limited their possibility to raise concerns that they had previously voiced. Firstly, at COP3, it was NA1 Parties that requested that the debate on the Brazilian Proposal was formally reintroduced into the process. A1 Parties, that had refused to accept the proposal as an entry point for a new protocol on the basis of its methodological flaws, could hardly argue that exploring the scientific and methodological aspects of the proposal would be uninteresting. As a compromise, the issue was therefore placed in the SBSTA. At that stage, NA1 Parties could hardly have anticipated the consequences of placing the issue under SBSTA auspices. Secondly, in the wake of having adopted the KP, there was in fact much time to elaborate on the details of the Brazilian Proposal since the process that followed on Kyoto focused on specifying details of the newly established treaty. Negotiations for new agreements, in which historical responsibility could play a role, were not on the agenda. This allowed time, besides specifying the detailed rules for the $\mathrm{KP}$, to also elaborate on details of the Brazilian Proposal. From an NA1 perspective, this at least kept the issue on the negotiating table.

In 2008, at the time of the final report by MATCH (UNFCCC, 2008b, 2008c), the concept of historical responsibility had already begun to filter into official negotiations via new negotiating mandates. It gradually became less dependent on meaning due to its structural position under CBDR while simultaneously it exerted growing influence over the interpretations of CBDR. An Indian submission after Copenhagen was in line with this: "Acceptance by developed countries of 
the principle of their historical responsibility and their undertaking to make credible cuts in GHG emissions is the starting point for a fair and equitable agreement" (UNFCCC, 2010a: 10).

\section{8 onward: Historical responsibility as floating signifier}

Once the strongly defended rationale of objectivity approached the end of the road with respect to dealing with political controversy over historical responsibility, difference and plurality emerged. Alternative positions were, and still are, being made clearer, drawing on the content developed within the discourse constructed around a traditional view of science yet challenging the exclusiveness to objectivity enabled by its core rationale.

This became most apparent during AWG-LCA5, on a possible new treaty under the Convention, when several Parties requested further clarification on historical responsibility. The Chair responded by organizing "a technical briefing to enable Parties to receive and share views on the concept of historical responsibility as a guide to future action" (UNFCCC, 2009a). Delegations of e.g. Brazil, India, and China put forward highly distinctive interpretations of historical responsibility (Brazil, 2009; China, 2009; India, 2009). The diversity of their own and others' interpretations had been hinted at before (African-Group, 2008; AOSIS, 2008; Brazil, 2008; Ecuador, 2008; Ghana, 2008; Japan, 2008; UNFCCC, 2006a, 2006b, 2008a), yet from the LCA5 briefing onward, articulations of historical responsibility have taken on more distinctly divergent structures. However, differing in scale and method, they all articulate responsibility as a matter of proportionality to contribution.

Other recent articulations clearly structure historical responsibility as conceptually rather than proportionally important. A workshop report on a shared vision, capturing statements by the Japanese and other governments (Japan, 2008, 5), reads: "Achieving a long-term global goal requires a global response, with all Parties taking action in line with their common but differentiated responsibilities and respective capabilities. Together with a recognition of past emissions, these responsibilities and capabilities mean that developed countries must lead global efforts to reduce emissions" (UNFCCC, 2008a, 3-4). This way of structuring historical responsibility is much more open to horse-trading commitments in a kind of pledge-and-review approach.

No countries are any longer unwilling in principle to accept explicit language on historical responsibility. The struggle now concerns how to position the concept in the wider discursive structure. Currently a whole set of bracketed references in texts facilitating AWG-LCA and -KP negotiations serves this purpose, references sometimes referring to a conceptual and sometimes to a proportional understanding of historical responsibility (see e.g. UNFCCC, 2009b, 5; 2009c, 3; 2009d, 4, 20 and 45; UNFCCC, 2009e, 15; 2010b, 15).

Reference to historical responsibility is thus made both as an attempt to lock its meaning to the A1/NA1 division accepting a conceptually moral obligation yet not proportionality, and to base it on individual Parties' proportional contribution to change. There is also now a hybrid version resting on accepting A1/NA1 as core categories while asking for a collective A1 responsibility in proportion to contribution (cf. China 2009; India 2009). Further, as with per capita, articulations on differentiation based on debt (guilt rather than responsibility) and, again, the PPP (liability to pay) are emerging in the periphery of historical responsibility discourse.

Figure 5 show important signifiers in how discourse on (historical) responsibility was structured in negotiations from 2005 onwards. Discussions on historical responsibility in proportion to contribution are becoming even more elevated as a privileged signifier in itself, and more elaborated, but simultaneously diversified in several filled signifiers. Also, explicit references are now attempting to articulate and close discourse on historical responsibility as a conceptual idea. The PPP and the notion of carbon debt is also developed and structured as a means to differentiate responsibility in proportion to contribution. They are often elaborated in close connection to historical responsibility, yet stress the need to rectify damage by paying rather than to bolster a responsibility to act. 
The consensus orientation of the negotiations limits the possibility of a set of distinct structures. Since many Parties now refuse to consider the possibility of structuring historical responsibility as emptied or filled (based on claims for objectivity), new rationales for consensus have to be crafted if negotiations are to move forward. Struggles over the preferential right to articulate historical responsibility boil down to the broader question of whether commitments should be distributed based on an allocation principle amounting to a global emissions cap or whether they should be decided based on horse-trading between Parties' willingness to contribute to a global objective. Accordingly, it is at the heart of current climate negotiations.

Currently, distinct articulations are given deliberative space, opening the political sphere of historical responsibility by structuring it as a floating signifier, where antagonism is allowed and where legitimacy can be built by using conflict to agonize differences (cf. Mouffe, 2005). This strategy may pave the way for future agreements on historical responsibility. The 2010 meeting in Cancún for the first time ever saw a COP, as opposed to a Subsidiary Body conclusion, adopting language explicitly linking contribution to historical responsibility:

\section{Acknowledging that the largest share of historical global emissions of greenhouse gases originated in developed countries and that, owing to this historical responsibility, developed country Parties must take the lead in combating climate change and the adverse effects thereof (UNFCCC, 2011: 6).}

Indeed, this decision does not settle whether historical responsibility should be structured as proportionally or conceptually important, yet it underscores its growing recognition as a privileged signifier within responsibility negotiations. No longer do historical responsibility negotiations have to anchor their existence in a presupposed link between contribution and differentiated responsibility. The decision also show broad consensus across north-south lines about the need to acknowledge historical responsibility. Nevertheless, as the concept has now gained clear official recognition on the UN climate agenda, the struggle to pin down historical responsibility will likely continue and intensify, as the wider negotiating texts on the table indicate (Friman \& Hjerpe, 2014).

The ability of these negotiations to deliver recognition in sets of AWG-KP conclusions (cf. UNFCCC, 2006c: 10) and the recent COP decision could also be seen as the first successful steps towards constructing an agonistic rationale for further negotiations, one where mutual understanding and passionate debate could deliver consensuses that acknowledge conflict and in turn enhance legitimacy. Designing the regime to be able to meet this challenge is of key importance for future negotiations and research.

\section{Discussion: implications for the UNFCCC}

Structuring discourse by emptying or filling privileged signifiers are no longer widely accepted rationales to build consensus. As a result of the many years of constrained negotiations on scientific and methodological aspects of the Brazilian proposal, the strongest proponents of differentiating responsibilities in proportion to contribution to climate change now have many tools for approaching the issue. The years during which negotiations on historical responsibility where guided by a rationale of objectivity have mobilized capacity to rearticulate the concept in structures pinpointing, more clearly, the proportional understanding of the concept, in turn allowing more space for conflict over equity to be aired. Currently, this knowledge is used as accepted knowledge on which to build various clearly distinguishable versions of proportional historical responsibilities. Similarly, proponents of a more conceptual understanding are starting to pin down the concept in more direct relation to dividing countries into developed and developing states, making the difference between discourses structured along proportional as well as conceptual understandings of the moral significance of history clearer too.

Since achieving consensus inevitably excludes alternatives, while the alternatives at the same time are now getting clearer, understanding and discussing the rationales for such exclusion are of crucial importance as a starting point to discuss how to increase legitimacy. As long as negotiators 
maintain these alternatives, they are validated by virtue of the UNFCCC regime design. First accepting stakeholders and then excluding core stakes through tacit discursive mechanisms ought to have contributed to less legitimate consensuses than expected from the process. The fact that new discourse is currently taking shape offers an opportunity to lift the discussion on how to design discursive rationales for consensus that to forge more legitimate outcomes.

At present, the concept of historical responsibility is not only established, but also widely accepted; this is also reflected in the fact that it has now entered into COP decision 1/CP.16. Historical responsibility has grown into an established and important node in responsibility negotiations more generally, and as the established and unquestioned core of its own discourse. It is no longer acceptable to raise concerns as to its validity as a central node, which was definitely possible before about 2005, with a few concerns also raised between 2005 and 2008.

One aspect of historical responsibility negotiations that parallels the entrenchment of the concept, straight through the 20 years of negotiating this issue, is whether historical responsibility should be understood in proportional or conceptual terms. As questioning historical responsibility per se has become inconceivable, the struggle between proportional and conceptual interpretations has grown in importance. This can be explained as a reaction to the establishment of the concept; if the concept cannot be wished away, gaining the preferential right to interpret it becomes all the more important. Likewise, it is also possible to explain the acceptance of historical responsibility, to begin with, by the fact that it has become more viable to understand historical responsibility in conceptual terms. If it is not understood solely in proportional terms, those actors in the discourse who oppose the proportional interpretation can still accept the historical responsibility concept by structuring it in relation to regional differentiation, while arranging individual countries' quantified commitments based on for example capabilities to act.

It would be possible to understand the agreed-on nodes as tacit bases at the center of the discourse. However, in order to understand the implications for future climate negotiations, it is both more compelling and more meaningful to focus on what has been excluded from agreement. The significance of historical responsibility for the differentiation of commitments will be defined by the struggle over how to operationalize the concept. If this conflict eventually settles into agreement, it will have a much larger effect on politics than will clearly establishing historical responsibility as a guiding principle.

On the other hand, agreements become important cornerstones motivating further negotiations to attach new concepts to the central nodes of discourse so that the concept is slowly locked into a specific meaning and alternative interpretations are gradually excluded. If the core of this discourse is understood as concerning the highly conflictive - as opposed to more solidifiedsubstance, then finding ways to deal with substantive conflict to arrive at agreement becomes a matter, from the discourse perspective, of excluding conflict from agreement without excluding those who express conflicting statements. The negotiating practice legitimizes all Parties' stands in the discourse, while demanding that conflict be excluded from consensus agreement. However, the rationales for exclusion have to be cleverly crafted to produce legitimate outcomes that spur implementation. This is the great challenge for UNFCCC negotiating practice.

Resolving the core conflict over responsibility distribution does not, and cannot, get enough attention on the cramped COP agenda. This is so because the procedural means to go about this, for the COP, is either to defer such issues to the subsidiary bodies or to initiate open-ended informal negotiations. The former option would mean that the issue lands in the SBI or SBSTA, whose mandates do not really suit a cross-cutting issue such as this. Nor is the latter option particularly attractive, since an informal group terminates with the end of a session, which would disfavor negotiations of this long-term, dynamic issue that is unlikely to disappear from the agendas.

One way ahead would be to create a newly designed body under UNFCCC auspices that relieves the overloaded COP (and CMP) agenda of discussions of how to understand principlecommitment linkages. In one sense, such a body would be similar to a Committee of the Whole 
(COW) whose objective is normally to discuss cross-cutting themes existing among subsidiary bodies. On the other hand, granting such a COW permanency and establishing a clear mandate to interpret principle-commitment linkages would provide a permanent home for some of the core conflicts concerning responsibilities. Not least, this body would provide an opportunity to discuss equity as a driver of the operationalization of principles via commitments. Building on such conclusions and draft decisions, other subsidiary bodies could model implementation policy in certain areas, and define common ground on technical matters that follow from linking principles to new commitments.

\section{Conclusions}

To understand efforts to build consensus in over 20 years of negotiating historical responsibility, this article has turned to the highly conflictive issue of responsibility negotiations in general and historical responsibility in particular. While UNFCCC negotiating practice is arguably designed to build the legitimacy of its outcomes by being oriented towards consensus, this is undermined by the tacit rationales that exclude conflict from agreement. Agreements of the kind emerging from the negotiating practice of the UNFCCC seem to gradually encircle rather than solve conflict by using rationales to exclude conflict while solidifying the language and concepts around which the conflict revolves. Arbitrary and ultimately conflictive concepts are built into the regime, such as "historical responsibility", making the core conflict inescapable, at least as long as the stakes involved are growing.

Given the current situation in climate negotiations, stakes are indeed growing. A quantification of a global goal is being negotiated alongside quantifications of mitigation commitments. A global temperature goal could indeed guide negotiations on how a universal responsibility should be differentiated between developed and developing countries. Yet the process has, to a much lesser extent, managed to prove that it can distribute responsibilities in such a way that the UNFCCC's objective, as it is now being quantified, can be achieved. For each year that passes by without indication that we are on track towards achieving the global temperature goal, the stakes in responsibility negotiations increase. Under such conditions, conflict over the validity of the various assessments of the past underlying certain distributions of responsibility is likely to intensify.

Based on how historical responsibility has been negotiated over the last 20 years, this article shows that there is a growing need to air conflict in a forum designed to address one of the core issues of climate negotiations: responsibility. Such a body could help build the legitimacy of outcomes by illuminating rather than obscuring conflict. The mandate for such a body, however, needs careful consideration. The body should not be designed so that the process is held hostage by conflict; it must be designed as to use conflict to raise legitimacy of outcomes, not to undermine the possibility of reaching them to begin with. The challenges posed by this task is beyond the scope of this paper, however, drawing on methods put forward in the extensive literature on peace and conflict resolution would be advisable.

\section{Acknowledgements}

This work was supported by Formas (grant no. 2011-779), and the Swedish Energy Agency (grant no. P35462-2). I would like to thank the anonymous reviewers for constructive comments, and Björn-Ola Linnér and Mattias Hjerpe for comments on earlier versions of this article.

\section{References}

African-Group. (2008). AWG-LCA4: Workshop presentation (shared vision for long-term cooperative action), Poznan 2008. Retrieved 25.05.2010, from http://unfecc.int/meetings/ad hoc working groups/lca/items/4668.php

Alvesson, Mats. (2003). Postmodernism och samhällsforkning. Malmö: Liber. 
AOSIS. (2008). AWG-LCA4: Workshop presentation (shared vision for long-term cooperative action), Poznan 2008. Retrieved 25.05.2010, from http://unfccc.int/meetings/ad hoc working groups/lca/items/4668.php

Bergström, Göran, \& Boréus, Kristina. (2005). Diskursanalys. In G. Bergström \& K. Boréus (Eds.), Textens mening och makt: Metodbok i samhällsvetenskaplig text- och diskursanalys (Second ed.). Lund: Studentlitteratur.

Bourdieu, Pierre. (1981). The Specificity of the Scientific Field. In C. C. Lemert (Ed.), French Sociology. Rupture and Renewal Since 1968 (pp. 257-292). New York: Columbia University Press.

Brazil. (2008). AWG-LCA4: Workshop presentation (shared vision for long-term cooperative action), Poznan 2008. Retrieved 25.05.2010, from http://unfccc.int/meetings/ad hoc working groups/lca/items/4668.php

Brazil. (2009). AWG-LCA6: Technical Briefing (José Miguez), Historical Responsibility: A Brazilian Perspective. Retrieved 26.05.2010, from http://unfccc.int/files/meetings/ad hoc working groups/lca/application/pdf/5 brazil.pdf

Butler, Judith, Laclau, Ernesto, \& Žižek, Slavoj. (2000). Contingency, Hegemony, Universality: Contemporary Dialogues on the Left. London and New York: Verso.

Caney, Simon. (2006). Environmental Degradation, Reparations, and the Moral Significance of History. Journal of Social Philosophy, 37(3), 464-482.

China. (2009). AWG-LCA6: Technical Briefing (Teng Fei), Historical Responsibility: from a perspective of per capita cumulative emissions. Retrieved 26.05.2010, from http://unfccc.int/files/meetings/ad hoc working groups/lca/application/pdf/6 china.pdf

Cordonier Segger, Marie-Claire, Kahlfan, Ashfaq, Gehring, Markus, \& Toering, Micehelle. (2003). Prospects for Principles of International Sustainable Development Law after the WSSD; Common but Differentiated Responsibilities, Precaution and Participation. RECIEL, 12(1), 54-68.

den Elzen, Michel, Berk, Marcel, Schaeffer, Michiel, Olivier, Jos, Hendriks, Chris, \& Metz, Bert. (1999). The Brazilian Proposal and other options for international burden sharing: An evaluation of methodological and policy aspects using the FAIR model. the Dutch National Institute of Public Health and the Environment.

Depledge, Joanna. (2005). The Organization of Global Negotiations: Constructing the Climate Change Regime. London: Earthscan.

Ecuador. (2008). AWG-LCA4: Workshop presentation (shared vision for long-term cooperative action), Poznan 2008. Retrieved 25.05.2010, from http://unfecc.int/meetings/ad_hoc_working_groups/lca/items/4668.php

ENB. (1995). AGBM2 Report: Oct 30 - Nov 3, 1995. Earth Negotiations Bulletin, 12(24).

Fairclough, Norman. (2003). Analysing Discourse: Textual Analysis for Social Research. London and New York: Routledge.

Friman, Mathias., \& Hjerpe, Mattias. (2014). Agreement, significance, and understandings of historical responsibility in climate change negotiations. Climate Policy. doi:10.1080/14693062.2014.916598.

Friman, Mathias, \& Linnér, Björn-Ola. (2008). Technology obscuring equity: historical responsibilities in UNFCCC negotiations. Climate Policy, 8(4), 339-354.

Friman, Mathias, \& Strandberg, Gustav. (2014). Historical responsibility for climate change: science and the science-policy interface. WIREs Climate Change, In press (Online first: 2014. doi: 10.1002/wcc.270).

Ghana. (2008). AWG-LCA4: Workshop presentation (shared vision for long-term cooperative action), Poznan 2008. Retrieved 25.05.2010, from http://unfccc.int/meetings/ad_hoc_working_groups/lca/items/4668.php

Gottardis, Andreas. (2007). The Critical Theoretical Quarrel over the Conditions of Emancipation: Habermas vs. Honneth. Paper presented at the Statsvetenskapliga Förbundets Årsmöte, Norrköping.

Hajer, Maarten A. (1995). The politics of environmental discourse: ecological modernization and the policy process. Oxford: Clarendon.

Hurd, Ian. (1999). Legitimacy and Authority in International Politics. International Organization, 53(2), 379-408.

Hurd, Ian. (2011). Choices and Methods in the Study of International Organizations. Journal of International Organizations Studies, 2(2), 7-22.

Höhne, Niklas, \& Blok, Kornelius. (2005). Calculating historical contribututions to climate change. Climatic Change, 71(2), 141-173. 
India. (2009). AWG-LCA6: Technical Briefing (Prodipto Ghosh), Quantifying Historic

Differentiated Responsibility: Concept and Empirical Results. Retrieved 26.05.2010, from

http://unfccc.int/files/meetings/ad hoc working groups/lca/application/pdf/7 indial.pdf

Interview. (2008a). Interview with de Araujo, Muylaert Maria Silvia, Rio de Janeiro, 17.11.2008.

Interview. (2008b). Interview with Meira Filho, Luiz Gylvan. Institute of Advanced Studies of the University of São Paulo (Instituto de Estudos Avançados da USP), 12.11.2008.

Interview. (2008c). Interview with Miguez, José Domingos Gonzalez. Federative Republic of Brazil, Ministry of Science and Technology, Brasilia, 31.10.2008.

Interview. (2009). Interview with Teng Fei. Bela Center, Copenhagen, 09.12.2009.

Japan. (2008). AWG-LCA4: Workshop presentation (shared vision for long-term cooperative action), Poznan 2008. Retrieved 25.05.2010, from http:/unfccc.int/meetings/ad hoc working groups/lca/items/4668.php

Johnstone, Ian. (2011). The power of deliberation: international law, politics, and organizations. New York: Oxford University Press.

Laclau, Ernesto. (1996). Emancipation(s). London and New York: Verso.

Laclau, Ernesto. (2000a). Constructing Universality. In J. Butler, E. Laclau \& S. Žižek (Eds.), Contingency, Hegemony, Universality: Contemporary Dialogues on the Left (pp. 281307). London and New York: Verso.

Laclau, Ernesto. (2000b). Identity and Hegemony: The Role of Universality in the Constitution of Political Logics. In J. Butler, E. Laclau \& S. Žižek (Eds.), Contingency, Hegemony, Universality: Contemporary Dialogues on the Left (pp. 44-89). London and New York: Verso.

Laclau, Ernesto, \& Mouffe, Chantal. (2001). Hegemony and socialist strategy: towards a radical democratic politics. London: Verso.

MATCH. (2003). Meeting Report, Third expert meeting on scientific and methodological aspects of the proposal by Brazil, 8-9 September 2003, Berlin. Retrieved 30.12.2005, from http://www.match-info.net/data/report 3rd Expert Meeting final.PDF

Meira Filho, Luiz Gylvan, \& Miguez, José Domingos Gonzalez. (2000). UNFCCC technical Note: Note on the Time-Dependent Relationship between Emissions of Greenhouse Gases and Climate Change. from http://unfccc.int/resource/brazil/documents/proposta.pdf

Miguez, José Domingos Gonzalez. (1997). Speech on the Opening Session of the Seventh Session of AGBM. Retrieved 11.10.2010, from http://www.mct.gov.br/index.php/content/view/18355.html - inexistente

Mouffe, Chantal. (2005). On the political. London and New York: Routledge.

Müller, B. (2002). Equity in climate change: The great divide. OIES report EV 31. Oxford: Oxford Institute for Energy Studies. Retrieved 31.01.2014, from http://www.oxfordenergy.org/2002/03/equity-inglobal-

climate-change-the-great-divide.

Müller, Benito, Höhne, Niklas, \& Ellermann, Christian. (2007). Differentiating (Historic) Responsibilities for Climate Change: Summary Report.

Neumayer, Eric. (2000). In defence of historical accountability for greenhouse gas emissions. Ecological economics, 33(2), 185-192.

Rajamani, Lavanya. (2000). The Principle of common but differentiated responsibilities and the balance of commitments under the climate regime. RECIEL, 9(2), 120-131.

Ringius, Lasse, Torvanger, Asbjørn, \& Underdal, Arild. (2002). Burden Sharing and Fairness Principles in International Climate Policy. International Environmental Agreements: Politics, Law and Economics, 2(1), 1-22.

Sabel, Robbie. (2006). Procedure at international conferences: a study of the rules of procedure of international inter-governmental conferences Cambridge: Cambridge University Press.

Sarewitz, Daniel. (2004). How science makes environmental controversies worse. Environmental Science and Policy, 7(5), 385-403.

Seyersted, Finn. (2008). Common Law of International Organizations. Leiden and Boston: Martinus Nijhoff Publishers.

Stone, Christopher D. (2004). Common but Differentiated Responsibilities in International Law. The American Journal of International Law, 98(2), 276-301.

UN. (1969). Vienna Convention on the Law of Treaties. United Nations, Treaty Series, vol. 1155, p. 331.

UN. (1990). Protection of Global Climate for Present and Future Generations of Mankind. UNGA Resolution 45/212.

UN. (1991a). INC1: Report, Washington, 1991. A/AC.237/6. 
UN. (1991b). INC2: Compilation of possible elements for a Framework Convention on Climate Change submitted by delegations, Geneva, 1991. A/AC.237/Misc.5/Add.3.

UN. (1991c). INC3: Consolidated text based on proposals regarding principles and commitments, Nairobi, 1991. A/AC.237/Misc.9.

UN. (1991d). INC3: Report, Nairobi, 1991. A/AC.237/12.

UN. (1992a). The Framework Convention on Climate Change. A/AC.327/18 (Part II)/Add.1.

UN. (1992b). INC4: Report, Geneva, 1991. A/AC.237/15.

UN. (1992c). INC5, Part I: Report, New York, 1992. A/AC.327/18 (Part I) (pp. 10 26).

UN. (1994). INC11: Matters relating to commitments, comments from Parties, New York 1995. A/AC.237/Misc.43.

UN. (1995). INC11: Matters relating to commitments, comments from Parties, New York 1995. A/AC.237/Misc.43/Add.1.

UNFCCC. (1995). COP1: Report (Addendum I), Berlin 1995. FCCC/CP/1995/7/Add.1.

UNFCCC. (1996). COP2: Adoption of the rules of procedure, Geneva 1996. FCCC/CP/1996/2.

UNFCCC. (1997a). AGBM7: Implementation of the Berlin Mandate: Additional proposals from Parties. FCCC/AGBM/1997/MISC.1/Add.3.

UNFCCC. (1997b). AGBM8: Consolidated Negotiating Text. FCCC/AGBM/1997/7.

UNFCCC. (1997c). COP3: Organizational matters, Adoption of the Rules of Procedure, Note by the President. FCCC/CP/1997/5.

UNFCCC. (1998a). COP3: Report, Addendum 1 (including the Portocol), Kyoto 1997. FCCC/CP/1997/7/Add.1.

UNFCCC. (1998b). COP3: Report, Kyoto 1997. FCCC/CP/1997/7.

UNFCCC. (1998c). SBSTA8: Report, Bonn 1998. FCCC/SBSTA/1998/6.

UNFCCC. (1998d). SBSTA9: Report, Buenos Aries 1998. FCCC/SBSTA/1998/9.

UNFCCC. (2003). SBSTA17: Report, New Delhi 2002. FCCC/SBSTA/2002/13.

UNFCCC. (2004). SBSTA19: Report, Milan 2003. FCCC/SBSTA/2003/15.

UNFCCC. (2006a). AWG-KP2: In session workshops, presentation by Brazil, Nairobi 2006. Retrieved 13.11.2007, from http://unfccc.int/files/meetings/cop 12/insession workshops/application/pdf/061107 5 awg brazil 1.pdf

UNFCCC. (2006b). AWG-KP2: In session workshops, presentation by South Africa, Nairobi 2006. Retrieved 13.11.2007, from http://unfccc.int/files/meetings/cop 12/insession workshops/application/vnd.ms-powerpoint/061107 7 awg sa.pps

UNFCCC. (2006c). AWG-KP2: Report, Nairobi 2006. FCCC/KP/AWG/2006/4.

UNFCCC. (2006d). SBSTA24: Report, Bonn 2006. FCCC/SBSTA/2006/5.

UNFCCC. (2008a). AWG-LCA4: Workshop report on a shared vision for long-term cooperative action, Poznan 2008. FCCC/AWGLCA/2008/CRP.6.

UNFCCC. (2008b). SBSTA28: Report, Bonn 2008. FCCC/SBSTA/2008/6.

UNFCCC. (2008c). SBSTA28: Results of the work on scientific and methodological aspects of the proposal by Brazil, Submissions from Parties. FCCC/SBSTA/2008/MISC.1.

UNFCCC. (2009a). AWG-LCA6: Summary of views expressed during AWG-LCA5. FCCC/AWGLCA/2009/9.

UNFCCC. (2009b). CMP5: Proposal for amendments (Algeria, Benin, Brazil and 34 other states). $\mathrm{FCCC} / \mathrm{KP} / \mathrm{CMP} / 2009 / 9$.

UNFCCC. (2009c). CMP5: Proposal for amendments (Colombia). FCCC/KP/CMP/2009/8.

UNFCCC. (2009d). COP15: Draft protocol to the Convention (Costa-Rica). FCCC/CP/2009/6.

UNFCCC. (2009e). COP15: Draft protocol to the Convention (Tuvalu). FCCC/CP/2009/4.

UNFCCC. (2010a). AWG-LCA10: Submissions from Parties, additional views. FCCC/AWGLCA/2010/MISC.2/Add.1.

UNFCCC. (2010b). COP16: Proposed protocol to the Convention (Grenada). FCCC/CP/2010/3.

UNFCCC. (2011). COP16: Report (addendum 1), Cancún 2010. FCCC/CP/2010/7/Add.1.

UNFCCC. (2013). COP18: Report, Doha 2012. FCCC/CP/2012/8.

Winther Jørgensen, Marianne, \& Phillips, Louise. (2002). Discourse Analysis as Theory and Method (S.-E. Torhell, Trans.). London, Thousand Oaks, New Delhi: SAGE Publications.

Yamin, Farhana, \& Depledge, Joanna. (2004). The International Climate Change Regime: A Guide to Rules, Institutions and Procedures. Cambridge: Cambridge Univeristy Press. 